\title{
Fluoretação da água: uma questão de política pública - o caso do Estado do Ceará
}

\author{
Water fluoridation: a matter of policy - the state \\ of Ceará, Brazil
}

Lana Bleicher ${ }^{1}$

Francisco Horácio da Silva Frota 2

\footnotetext{
1 Departamento

de Odontologia Social

e Pediátrica, Faculdade

de Odontologia da UFBA.

Av. Araújo Pinho 62,

4o andar, Canela, 40110-150,

Salvador BA.

lana@ufba.br

2 Universidade Estadual

do Ceará.
}

Abstract This study tries to analyze how drinking water fluoridation has developed in Ceará state so contributing to nationwide policy understanding. Nineteen people involved in this process were interviewed, among the state water company, Fundação Nacional de Saúde and Secretaria Estadual da Saúde do Ceará workers and Grupo Estadual de Controle de Flúor members. A documental search in the files of institutions mentioned above, besides dental journals, newspapers and State Official Daily complemented the finds of the interviews. Public Administration actuation, by means of Sesp Foundation and national programs were analyzed, as well as the state actuation through its water company and also the role of social control in the process. Finds show that although most part of the population receives fluorated water in Ceará state due to the State actuation, there was an important role of the Federal State in the implementation of this measure. The State company performance was restricted to large water distribution systems. Fundação $\mathrm{Na}$ cional de Saúde fluorated small systems and was a reference on the matter in the state. It was not found evidence of society participation in what concerns this theme, which was restrict to academic debate.

Key words Water fluoridation, Health policy, Water supply, Sanitation
Resumo Este estudo busca descobrir como a fluoretação das águas se desenvolveu no Ceará, contribuindo assim para o entendimento da política nacionalmente. Foram realizadas entrevistas com 19 atores envolvidos no processo, entre técnicos da companhia estadual de abastecimento d'água, da Fundação Nacional de Saúde, da Secretaria Estadual da Saúde do Ceará e do Grupo Estadual de Controle do Flúor. Procedeu-se também a uma pesquisa documental nos arquivos dessas instituições, além de informativos da categoria, jornais de grande circulação e Diário Oficial do Estado, que complementou os achados das entrevistas. Foram analisadas as atuações do poder público federal (Fundação Sesp/Fundação Nacional de Saúde e programas nacionais) e estadual (companhia de abastecimento de água); bem como o papel do controle social no processo. Os achados apontam que, no Ceará, embora a maior parte da cobertura populacional por água tratada se deva à atuação estadual, esta esteve fortemente dependente de financiamento federal para sua implementação. Sua atuação foi restrita a grandes sistemas. A Fundação Nacional de Saúde, além de atuar em pequenos sistemas, constituiu-se numa referência em relação ao assunto no estado. Não foram encontrados indícios de participação efetiva da sociedade em relação ao tema, ficando este circunscrito aos meios técnicos.

Palavras-chave Fluoretação da água, Política de saúde, Abastecimento de água, Saneamento 


\section{Introdução}

No Brasil, a fluoretação da água está prevista em lei federal, conta com o suporte de programas nacionais de financiamento e tem o apoio de gerações de sanitaristas envolvidas em sua defesa. No entanto, só alcança, ainda, pouco mais do que a metade da população. Para auxiliar a compreensão desse problema, os autores analisam o desenvolvimento da fluoretação no estado do Ceará - que ainda não atingiu completamente o potencial de cobertura. São objetivos deste artigo tratar do papel desempenhado pelas instituições relacionadas ao saneamento - o que nos remete à atuação das diferentes esferas de governo -, perceber como a implementação da medida foi influenciada pela política de financiamento e discutir a existência de participação social no processo. O período estudado tem como delimitadores os anos de 1983, primeira iniciativa de fluoretação da água em Fortaleza, e 1994, início da fluoretação da Estação de Tratamento de Água da Serra da Ibiapaba.

\section{Os primeiros passos da fluoretação}

Conhecer a história da fluoretação é elucidativo: ela surgiu com a descoberta de seu efeito colateral, a ocorrência de manchamento do esmalte dental, nos EUA, em 1908. A comprovação de que, em doses ideais, seria capaz de reduzir a cárie, ocorreu décadas depois - culminando com a fluoretação artificial da água em 1945. Entretanto, esta medida enfrentou fortes oposições, sendo acusada de atentar contra as liberdades individuais, uma vez que caberia ao indivíduo cuidar de sua própria saúde (Elwell \& Easlick11).

Para entender a controvérsia em torno da fluoretação da água nos Estados Unidos, é necessário contextualizá-la nas políticas públicas americanas, que não foram concebidas como um sistema de proteção universal, mas sim como ações focalizadas, voltadas para os grupos incapazes de prover seu sustento pela sua não inserção no mercado (Teixeira ${ }^{2}$ ). Dado que a adição de fluoretos à água é uma medida de proteção coletiva que independe de motivações individuais e tem um baixo potencial mercadológico (quando comparada à vigorosa indústria de bens para cuidados individuais), pode-se supor que não seria a estratégia mais adequada a uma política liberal. No Brasil, a fluoretação encontrou resistência consideravelmente menor, com o argumento dos possíveis efeitos colaterais que pudesse provocar.

\section{A fluoretação no Brasil}

A Fundação Sesp, que mais tarde seria incorporada à Fundação Nacional de Saúde, foi responsável pela adição de fluoretos à primeira cidade brasileira a contar com o benefício: Baixo Guandu (ES), em 1953. Neste trabalho, serão utilizadas as denominações Fundação Sesp ou Funasa, conforme o período em questão. A essa cidade se seguiram outras, onde a iniciativa se deveu ao poder municipal, cabendo ao nível estadual somente a assistência técnica, quando solicitada (Batalha ${ }^{3}$ ). Esta forma de intervenção encontra explicação em Costa ${ }^{4}$, que afirma: As décadas de 50 e 60 poderiam ser caracterizadas, na perspectiva do modelo gerencial, pela busca da autonomia dos serviços de saneamento, que efetivamente experimentam diversas formas de gestão (p. 60). Mais à frente, ele afirma que $54 \%$ dos serviços de abastecimento d'água eram municipais.

Rezende \& Heller ${ }^{5}$ apontam que as raízes de tal modelo se encontram na Constituição Federal de 1934, que estabelecia a organização desses serviços de caráter local, gerando considerável desnível em relação ao desenvolvimento das políticas de saneamento por todo país. Embora não tenha sido desprezível o papel do poder estadual no início da fluoretação das águas, percebe-se que foi gradualmente se expandindo, passando com o tempo a acumular as funções de estímulo e capacitação das companhias municipais com parte da execução. Nos anos 70, houve o primeiro sinal de participação da esfera federal com a aprovação da Lei Federal n. 6.050, de 1974, obrigando as estações de tratamento d'água, que daí por diante fossem construídas ou ampliadas, a realizarem planos relativos à fluoretação da água (Zanettí).

Cabe assinalar que mais importante que o estatuto legal da fluoretação foram os programas que buscaram ampliar o contingente de população abastecida por água tratada, a partir de linhas de financiamento. Duas iniciativas importantes ocorreram: em 1975, a Fsesp elaborou o Projeto de Fluoretação das Águas de Abastecimento Público, executado pelo Ministério da Saúde em convênio com o Instituto Nacional de Alimentação e Nutrição (Inan). Na década seguinte, a fluoretação da água foi fortemente incentivada pela alocação de recursos do 
Finsocial, via Banco Nacional de Habitação, para que as companhias de abastecimento d'água adicionassem flúor à água. Em relação ao projeto da Fsesp, Vianna \& Pinto $^{7}$ contrastam a meta pretendida pelo Inan (passar de uma cobertura inicial de $4,5 \%$ para $50 \%$ ) com o resultado alcançado: somente $16,9 \%$. Zanetti 6 avalia que o programa do $\mathrm{BNH}$ foi o primeiro momento de alocação significativa de verbas públicas em um programa de saúde bucal.

Ao compararmos os dados de cobertura por água fluoretada em números absolutos, verificaremos que, de 1972 a 1977, a cobertura populacional da fluoretação saltou de 3,3 para $7 \mathrm{mi}-$ lhões de habitantes, aumentando 3,24 vezes. De 1982 (25,7 milhões) a 1989 (62 milhões), o aumento foi de 2,4 vezes. No período de 1989 a 1996 (65,5 milhões), o crescimento foi de 1,05 vezes (Vianna \& Pinto $^{7}$, Pinto $^{8}, 9$, Campeão ${ }^{10}$ ). Percebe-se um alto crescimento percentual durante os anos 70, período de vigência do programa do Inan. Durante os anos 80, o aumento da cobertura prosseguiu, embora proporcionalmente não tão vigoroso, coincidindo com a alocação de recursos via BNH. Os anos 90 registram um aumento pífio, fazendo jus à ausência de políticas de financiamento à fluoretação.

Ao analisar as políticas do setor saneamento nos anos de 1970 e 1980, Costa 4 chama a atenção para a principal delas, o Planasa (Plano Nacional de Saneamento Básico), que existiu de 1971 a 1986. O autor considera que o critério de rentabilidade não foi o único a determinar os investimentos, perdurando o embate de duas lógicas: o autofinanciamento e a eqüidade social. Isto nos leva a entender porque a estratégia para o desenvolvimento da fluoretação, nesse período, tenha aparentemente se voltado para iniciativas com o poder central; e também permite supor que "assessoria e treinamento" não mais seriam suficientes para sensibilizar as companhias: dado que elas necessitavam autofinanciamento, eram necessários repasses financeiros.

Ainda que inicialmente a discussão do tema tenha se limitado aos círculos técnicos, a questão ganhou espaços mais ampliados com a democratização do país, como foi o caso das duas primeiras Conferências Nacionais de Saúde Bucal (1986 e 1993). Outros espaços de debate da fluoretação foram os Grupos Estaduais de Controle da Fluoretação (Gecof), cuja criação foi estimulada pelo Ministério de Saúde nos anos 80 (Zanetti6). Tinham por objetivos elaborar, executar, coordenar e supervisionar o Projeto de
Fluoração da Água em Sistemas de Abastecimento Público (Ceará11). Os Gecof eram instâncias de interlocução entre as instituições envolvidas com o projeto, mas foram sendo desativados sem que outros fóruns participativos se ocupassem de suas funções. No máximo, a atribuição de controle de fluoretação migrou para o interior das secretarias municipais ou estaduais de saúde, dando origem aos sistemas de vigilância sanitária que se instituíram nos anos 90.

Costa 4 explica que a tendência dentro do setor de saneamento durante a década de 1990 foi a substituição da lógica burocrática pela empresarial, marcada pela flexibilidade e competitividade, encontrando-se expressa no Projeto de Modernização do Setor de Saneamento (PMSS), iniciado em 1993 com financiamento do Banco Mundial. O autor chama a atenção para o fato de que a formulação da política nacional escapa da comunidade técnica de saneamento e passa para as mãos de economistas do Ministério do Planejamento, ocasionando embates entre estes dois grupos.

Oliveira Filho \& Moraes 12 demonstram como a criação, durante os anos 90, de programas federais de crédito a concessionários privados de saneamento e a interdição de empréstimos ao setor público apontaram o caminho da privatização do setor. A resistência por parte de trabalhadores e outros setores organizados foi capaz de obstaculizar algumas ofensivas, mas não todas. Nesse contexto, em que o saneamento deixa seu caráter de bem público para tornar-se serviço explorável pela iniciativa privada, há riscos de que ocorra no Brasil algo similar ao ocorrido no Reino Unido, onde, de acordo com Lowry e Evans13, não houve progresso na fluoretação após a privatização de grande parte das companhias de água.

\section{Procedimentos metodólogicos}

Foram realizadas pesquisa documental e entrevistas semi-estruturadas. A princípio, foi estabelecido que as entrevistas seriam realizadas com servidores da Cagece, Funasa e Secretaria Estadual da Saúde e membros do Grupo Estadual de Controle do Flúor do Ceará (Gecof). Entretanto, ao final de cada colóquio, era solicitado que se indicassem mais pessoas que o entrevistado julgasse aptas a contribuir para o esclarecimento do tema. Deste modo, foi possível descobrir personagens portadores de relatos extremamente ricos, que não haviam sido cogita- 
dos durante o período de elaboração do projeto da pesquisa. Ao final deste processo, foram realizadas 19 entrevistas. Este número foi considerado suficiente, pois permitiu que houvesse uma certa reincidência de informações, de modo a abarcar o tema na sua integralidade, tal como preconizado por Minayo ${ }^{14}$.

As entrevistas semi-estruturadas determinaram as principais diretrizes norteadoras do diálogo. $\mathrm{O}$ roteiro inicial destinado aos servidores da Funasa, Cagece e Secretaria Estadual de Saúde enfocava: os motivos que levavam à decisão de realizar a fluoretação; a política da instituição em relação à fluoretação, e como ela se verificava na prática; as relações institucionais; e o financiamento. As entrevistas com membros do Gecof abordavam o questionamento sobre os objetivos do grupo, suas discussões e decisões. Outros temas não previstos no roteiro inicial foram aflorando, e o roteiro foi sendo ampliado à medida que se avançava nesse momento da pesquisa.

As entrevistas foram gravadas, transcritas e, depois de repetidas leituras, eram assinaladas as categorias de investigação existentes no relato, como "Esfera Federal", "Esfera Estadual", "Controle Social”. A utilização do programa HyperResearch, da empresa ResearchWare, permitiu que os trechos das diversas entrevistas assinalados com o mesmo tema fossem agrupados. Desta forma, de posse de todos os fragmentos relativos a "controle social", por exemplo, foi construída a análise.

A pesquisa documental foi realizada nos arquivos dos jornais de grande circulação O Povo, com edições de 1976 a 1991, e Diário do Nordeste, com edições de 1992; informativos do Conselho Regional de Odontologia do Ceará (de 1983 a 1989) e do Sindicato dos Odontologistas do Estado do Ceará (1989); informativos da Cagece (1989); atas do Grupo Estadual do Controle do Flúor (1985); e Diário Oficial do Estado (1969 a 1989). De posse de cópia dos documentos, foram assinalados os trechos que remetiam aos temas de estudo, que, uma vez agrupados, foram analisados. Estes procedimentos permitiram remontar o desenvolvimento da política de fluoretação da água no Ceará e as visões dos atores envolvidos sobre a mesma.

O processo analítico se deu por triangulação, confrontando-se os achados da pesquisa documental, entrevistas e o diagnóstico realizado pelos autores publicado em Bleicher \& Frota 15 .

\section{Resultados e discussão: A fluoretação da água no Ceará}

Duas são as instituições envolvidas no processo de fluoretação da água no Ceará: o Sesp, atual Funasa, que já atuava no estado pelo menos desde 1954 (Bastos16); e a Companhia de Água e Esgotos do Ceará (Cagece), criada pelo poder estadual em 1971.

Os primeiros municípios a terem suas águas fluoretadas no Ceará foram Sobral e Quixeramobim, ainda nos anos 70, pela Fundação Sesp (Bleicher17). A fluoretação das águas da capital do estado, entretanto, angariou maior atenção.

\section{A companhia estadual e a fluoretação de Fortaleza}

Entre 1983 e 1986, período inicial de fluoretação de Fortaleza, foi adicionado flúor à água desta cidade, em função de convênio mediante o qual a companhia estadual de saneamento recebeu da esfera federal dez toneladas de fluossilicato de sódio. Percebe-se, portanto, que o investimento direto do poder federal na fluoretação da água de Fortaleza foi decisivo para seu início.

Foi nesse mesmo período que ocorreram as duas composições iniciais do Gecof - Grupo Estadual de Controle da Fluoretação. As atas das reuniões do grupo em 1984 sugerem uma situação favorável à obtenção de recursos financeiros do Banco de Desenvolvimento Econômico e Social, o que é compatível com o fato de o período em questão ser o de vigência do Programa de Fluoretação das Águas de Abastecimento Público, do BNDES/BNH/MS; no qual, segundo Zanetti6, grande soma de recursos do Finsocial foi destinada à fluoretação da água.

Entretanto, em 1986, a fluoretação da água de Fortaleza foi interrompida. Na época, o governo do estado, denominado de transição entre o ciclo dos coronéis (de 1963 a 1982) e o ciclo dos empresários (de 1986 aos dias atuais), enfrentou sérias dificuldades para manter a máquina administrativa (Farias18). A retomada da fluoretação em Fortaleza só ocorreu em 1989 (ETA $\left.{ }^{19}\right)$, já durante a vigência do ciclo dos empresários. Vale salientar que a lógica do equilíbrio orçamentário tem sido um de seus traços distintivos. O episódio descrito a seguir é ilustrativo. Em 1988, o diretor-presidente da Cagece recebeu a visita do Coordenador Nacional do Programa de Fluoretação da Água de Abastecimento Público do Ministério da Saúde. Este úl- 
timo alegava que a interrupção da fluoretação havia sido uma quebra contratual, por parte da Cagece, do convênio firmado com o Governo Federal; portanto, caberia à companhia reiniciar a fluoretação com recursos próprios. A solução apontada era o repasse ao usuário dos custos adicionais, idéia bem recebida pelo diretor-presidente da Cagece: É uma forma de obrigar a Companhia a manter a fluoretação, ao mesmo tempo em que injeta recursos na empresa, que necessita de verbas (Fortaleza ${ }^{20}$ ). De onde se deduz que a implantação da fluoretação na capital parecia atraente para a visão empresarial que se instalava no governo estadual.

Um dos motivos que pode ajudar a explicar a retomada da fluoretação na capital cearense foi o lançamento do Programa Nacional de Prevenção da Cárie Dental - Precad, pela Divisão Nacional de Saúde Bucal do Ministério da Saúde em 1989 (Brasil21). Neste programa, a prioridade foi dada à recuperação dos sistemas que haviam paralisado a fluoretação, meta que se pretendia atingir até o final de 1989. Visto que Fortaleza se enquadrava nessa condição, é razoável supor que tenha sido um dos sistemas a receber atenção especial do programa. O próprio governo estadual, em publicação no órgão de divulgação da Cagece, afirmava que a iniciativa era resultante de um convênio firmado com a Caixa Econômica Federal, mas que a partir do segundo ano, a fluoretação será feita com recursos próprios (ETA19).

Apenas mais um sistema operado pela Cagece recebeu adição de flúor: a Estação Jaburu, que desde 1994 fornece água fluoretada a sete municípios da serra de Ibiapaba. Como a estação de tratamento de Fortaleza também é responsável pelo fornecimento de água a mais dois municípios, com apenas dois sistemas a Cagece fornecia, em 1999, água fluoretada a 2.424 .862 habitantes (Bleicher \& Frota15). Percebe-se que o poder estadual se limitou a realizar a fluoretação em grandes sistemas. Os pequenos sistemas de abastecimento são aqueles com maior dificuldade de auto-sustentação, por perderem em economia de escala. Portanto, realizar a fluoretação em sistemas de grande porte não chega a ser comparável à dificuldade em implantá-la em sistemas pequenos - neste caso seria necessário haver incontestes ganhos sanitários que justificassem o investimento financeiro.

Abu-El-Haj22 analisa as políticas de saúde dos governos do ciclo dos empresários e afirma que, dentro de sua lógica pragmática, as medidas mais bem acolhidas eram as que demons- trassem, mediante cálculos financeiros, a melhor relação custo-eficácia, ilustrada no entusiasmo com o Programa Agentes de Saúde, implantado no Ceará antes de se constituir política nacional. Ora, a fluoretação da água não só tinha um custo per capita mais elevado em municípios menores, como também não houve, por parte do conjunto de atores sociais envolvidos em sua defesa, possibilidades em demonstrar sua eficácia.

Isto ocorre devido ao fato de não ter havido controle epidemiológico da medida. Excetuando-se o município de Icó (Martildes et al.23), abastecido pela Fundação Sesp, não foram encontrados registros de levantamentos epidemiológicos anteriores e posteriores ao inicio da fluoretação, para comprovar seu efeito. Em Fortaleza não foram realizados estudos com esta finalidade específica: os dados epidemiológicos realizados no município fazem parte dos estudos nacionais levados a cabo pelo poder federal. Vários entrevistados fazem referência à ausência de avaliação do impacto da fluoretação como um dos fatores que desmotivavam sua ampliação: E algumas vezes ele [o secretário de Desenvolvimento Urbano] abordou a gente [dentistas] pedindo, se fosse possível, nós fazermos uma avaliação do benefício. Era importante para a própria concepção do governo, em ver aquilo ali como uma necessidade mesmo, por uma questão de benefício realmente afirmada.

Outro fator apontado nas entrevistas foi a cultura institucional, exemplificada na fala de um funcionário da companhia estadual: A questão primeira é a cultura da empresa, que faltou a cultura e realmente faltou alguma pressão da sociedade em cima disso. Não tem ainda essa cultura, essa consciência da importância da fluoretação da água.

\section{O poder federal: \\ Fundação Sesp - Funasa}

Em 1999, Bleicher \& Frota15 verificaram que a Funasa oferecia água fluoretada a 371.748 cearenses, o que correspondia a apenas $13 \%$ da população do Ceará coberta por água fluoretada. Por outro lado, a Funasa realizava, em 1999, fluoretação em 38\% dos municípios que atendia, ao passo que na Cagece este número caía para $8 \%$.

Entrevistas com dentistas da Secretaria Estadual da Saúde do Ceará explicitam a reverência com que a Fundação Sesp era tratada, reconhecida como instituição com acúmulo de co- 
nhecimento na área: O Sesp já tinha uma história, uma bagagem de conhecimento nessa questão da fluoretação de água em alguns municípios do estado do Ceará.

Percebe-se um papel de estimulador da fluoretação, mesmo sobre sistemas da companhia estadual, como revela o trecho de uma entrevista com funcionário da Cagece: Quem começou a fazer a fluoretação no estado do Ceará foi o sistema dos SAAE [Sistema Autônomo de Água e Esgoto], que vieram gerenciados pela Fundação Nacional de Saúde, antiga Fundação Sesp. Então praticamente em todos os sistemas deles, eles usavam fluoretação de água. Isso para mim foi a maior pressão para a Cagece implantar em Fortaleza, porque não se justificava um bocado de sistemas de várias cidades pequenas do interior já com água fluoretada e Fortaleza sem ter.

No relato dos funcionários da Funasa, há reiteradas menções à formação dos profissionais que serviam à Fundação: os profissionais ficavam imbuídos destes referenciais e, usando as palavras de um engenheiro da instituição entrevistado, vestiam a camisa, lutavam. Nos locais em que a fluoretação não era implantada ou era abandonada, isso se devia ao fato de o conjunto de profissionais não ter vestido a camisa. A entrevista com um dentista da Secretaria Estadual de Saúde do Ceará também revela esse reconhecimento à qualificação dos recursos humanos: A gente tinha deles [funcionários da Fundação Sesp] uma idéia até de muito respeito, porque trabalhavam prevenção, trabalhavam a questão do tempo integral, dedicação exclusiva, tinha todo um histórico...

Percebe-se um diferencial da Fsesp em relação às outras instituições, no que tange a seus recursos humanos, o que pode ser cogitado como fator estimulante à fluoretação. Entretanto, uma instituição nos seus moldes, com forte preocupação com a qualificação de seus recursos humanos, ênfase na dedicação exclusiva e boa remuneração de seus quadros aparece como anacrônica para os dias atuais, em que predominam a terceirização, a ausência de vínculo empregatício e os contratos temporários nas três esferas de governo. Recomendam-se mais estudos que busquem avaliar o impacto da precarização das condições de trabalho e das privatizações no setor saneamento sobre a qualidade dos serviços prestados.

\section{Controle social e participação social}

A fluoretação da água é um excelente método preventivo, que atua nos organismos dos indivíduos até mesmo quando estes desconhecem que estão sendo atingidos. Falar em controle social da fluoretação remete mais comumente ao controle do Estado sobre os indivíduos que o inverso. O desenrolar dessa política no Ceará é um caso exemplar. Na fala dos atores, quando aparece o termo participação, não é da participação popular que se fala, mas da categoria odontológica e de técnicos do saneamento.

Assim, os usuários do sistema de abastecimento d'água não aparecem como protagonistas na história da fluoretação, quer na fala dos entrevistados, quer nas matérias de jornal. $\mathrm{Na}$ maior parte dos discursos presentes nestes jornais, a fluoretação aparece como bandeira exigida pelas entidades odontológicas, e a população - sobretudo a mais pobre, desinformada, que não conhece seus direitos, que precisa ser esclarecida - figura apenas como beneficiária passiva. A ignorância da população pode, inclusive, fazê-la se opor à fluoretação, ainda que isto tenha aparecido somente em um dos relatos, e não conste nos documentos. Em um episódio narrado, a população atribuía ao flúor na água $t u$ do o que acontecia dentro da casa, mesmo antes da fluoretação ter de fato se iniciado.

Portanto, o discurso construído é o da fluoretação como uma política em que caberia a participação dos técnicos, um assunto a ser debatido entre os que detêm o conhecimento "legítimo" sobre o assunto. A população fica caracterizada como objeto desta intervenção. Sintomático disto é que na composição do Grupo Estadual de Controle da Fluoretação, em 1989, figurava um representante da comunidade, mas não há referência ao modo pelo qual ele teria sido escolhido de forma a ter representatividade. Sua presença nem mesmo é recordada, quando indagamos outros membros do Gecof à época.

O não envolvimento de amplos setores da sociedade na questão é visível na fala de um funcionário da Cagece: Realmente faltou alguma pressão da sociedade em cima disso, eu nunca vi publicamente alguém chegar aqui na Cagece reclamando disso, e eu acho que isso foi que retardou esse processo.

A cobrança pela fluoretação da água é feita somente por técnicos: da Cagece, da Fsesp, e por cirurgiões-dentistas. Entretanto, mesmo a atuação das entidades odontológicas é vista 
como acanhada, na fala de entrevistados; havendo um sentimento de inoperância da categoria.

\section{Considerações finais}

O caso do Ceará mostrou como, em um estado de industrialização recente, a atuação da esfera federal teve papel preponderante, quer seja pelos programas de incentivo à fluoretação, quer pela ação direta da Fundação Sesp nos municípios em que atuava, ou, ainda, como influência

\section{Agradecimento}

Esta pesquisa contou com o apoio material da Capes, na forma de bolsa de mestrado.

\section{Colaboradores}

Lana B e Francisco HSF participaram igualmente em todas as etapas da elaboração do artigo.

\section{Referências}

1. Elwell KR, Easlick KA. Classificação e apreciação das objeções levantadas contra a fluoretação. São Paulo: DAE; 1966.

2. Teixeira SF. Estado sem cidadãos: seguridade social na América Latina. Rio de Janeiro: Fiocruz; 1994.

3. Batalha BL. Binômio fluoretação da água e cárie dentária. In: Anais do Seminário sobre Fluoretação PróLimp IV: programa de melhoria da qualidade da água. Jahu: Cetesb/Camu; 1984. p. 3-15.

4. Costa NR. Políticas públicas, justiça distributiva e inovação: saúde e saneamento na agenda social. São Paulo: Hucitec; 1998.

5. Rezende SC, Heller L. O saneamento no Brasil: políticas e interfaces. Belo Horizonte: UFMG; 2002.

6. Zanetti CHG. As marcas do mal-estar social no Sistema Nacional de Saúde: o caso das políticas de saúde bucal no Brasil dos anos 80 [dissertação]. Rio de Janeiro: Fiocruz; 1993.

7. Vianna SM, Pinto VG. Programa de fluoretação da água de abastecimento público: documento de trabalho 28. Brasília: Ipea/Iplan, CNRH; 1983.

8. Pinto VG. Saúde Bucal: panorama internacional. Brasília: Ministério da Saúde; 1990.

9. Pinto VG. A questão epidemiológica e a capacidade de sobre a companhia estadual. Mostrou também como o debate dessa política esteve circunscrito ao meio técnico, carecendo de controle social. Estes achados nos fazem supor que, para a obtenção de patamares mais elevados de cobertura por água tratada, será necessária a retomada de uma política de incentivo mediante financiamento federal, o impedimento da privatização do setor saneamento, a inscrição da medida na pauta de reivindicações populares e a adoção, por parte das instituições que realizam o abastecimento d'água, de uma cultura institucional que favoreça a fluoretação. respostas dos serviços de saúde bucal do Brasil [tese]. São Paulo: Faculdade de Saúde Pública da Universidade de São Paulo; 1992.

10. Campeão de cáries nunca mais. Rev $A B O$ Nacional 1996; 4(5):378-82.

11. Ceará. Secretaria da Saúde. Grupo de Controle do Flúor. Atas: reuniões ordinárias e extraordinárias realizadas de 14 jun. a 10 jul. 1985. f. 1.

12. Oliveira Filho A, Moraes LRS. Saneamento no Brasil: política e regulamentação. In: Conferência Nacional de Saneamento. Brasília; 1999. [mimeo.].

13. Lowry R, Evans D. The privatized water industry and public health: back to square one. Br Dent J 1999. 26; 186(12):597-8.

14. Minayo MCS. O desafio do conhecimento: pesquisa qualitativa em saúde. 4a ed. São Paulo: Hucitec; 1996.

15. Bleicher L, Frota FHS. Panorama da fluoretação da água de abastecimento em municípios cearenses. Rev ABOPREV 2003; 5(1):13-22.

16. Bastos NCB. Sesp/Fsesp: 1942 - Evolução histórica 1991. Recife: Comunicarte; 1993.

17. Bleicher L. Fluoretação das águas de abastecimento público no Ceará [dissertação]. Fortaleza (CE): Universidade Estadual do Ceará; 2000. 
18. Farias A. História do Ceará: dos índios à geração Cambeba. Fortaleza: Tropical; 1997.

19. ETA-Gavião. Lançado programa de fluoretação da água da RMF. Água Viva 1989; 4(19):4-5.

20. Fortaleza é a única capital onde falta água com flúor: fluoretação reduz em $60 \%$ cárie que atinge $98 \%$ da população. O Povo 1988; maio 11.

21. Brasil. Ministério da Saúde. Secretaria Nacional de Programas Especiais de Saúde. Divisão Nacional de Saúde Bucal. Programa Nacional de Prevenção da Cárie Dental - Precad. Brasília: MS; 1989.

22. Abu-El-Haj J. A mobilização do capital social no Brasil: o caso da reforma sanitária no Ceará. Fortaleza; 1998. [mimeo.].
23. Martildes MLR, Crisóstomo FP, Oliveira AWS. Avaliação da prevalência de cárie em escolares de Icó, Ceará, Brasil, após seis anos de fluoretação de águas de abastecimento público. Divulg Saúde Debate 1995; 10:38-42.

24. Vianna MIP. Estado e atenção odontológica no Brasil: um estudo sobre as políticas de saúde bucal na conjuntura pós-74 [dissertação]. Salvador: Universidade Federal da Bahia; 1988.

Artigo apresentado em 28/06/2005

Aprovado em 10/08/2005

Versão final apresentada em 1/09/2005 